\title{
SHORT-TERM ALTERATIONS IN SONGBIRD BREEDING SCHEDULE LEAD TO BETTER SYNCHRONIZATION WITH FOOD AVAILABILITY
}

\author{
Vicente García-Navas ${ }^{1,3}$ and Juan José Sanz ${ }^{1,2}$ \\ ${ }^{1}$ Área de Zoología, Departamento de Ciencias Ambientales, Facultad de Medio Ambiente, Universidad de Castilla-La Mancha, \\ Avenida Carlos III s/n 45071 Toledo, Spain; and \\ ${ }^{2}$ Departamento de Ecología Evolutiva, Museo Nacional de Ciencias Naturales-CSIC, Calle José Gutiérrez \\ Abascal 28006 Madrid, Spain
}

\begin{abstract}
Aвstract.-Birds can, to a limited extent, delay hatching after laying the first egg to synchronize hatching date to peak food availability by increasing the laying interval between eggs or postponing the start of incubation. However, hatching delays can be the result of energy costs of early reproduction. We report the phenomenon of hatching delays in a Blue Tit (Cyanistes caeruleus) population in two contrasting breeding seasons. We determined the occurrence of laying gaps and postponement of incubation, and the factors and consequences associated with each. We found that the clutch size, the occurrence of laying gaps, the onset of incubation, and the degree of synchrony with the food peak explained a significant proportion of the variance of hatching delays and that this trait was negatively related to hatching probability but positively related to nestling mass. Females that increased the laying interval between eggs experienced reduced hatching success. The incidence of gaps was largely determined by temperature, which suggests that it is a nondeliberate phenomenon. The extent of synchrony with the caterpillar peak was the main predictor of variation in the onset of incubation. Females that advanced their onset of incubation laid more eggs of better quality in comparison to those that exhibited a normal or delayed incubation schedule. Our study provides evidence that hatching delays are the result of both energy constraints and strategic decisions. Received 13 April 2010, accepted 27 July 2010.
\end{abstract}

Key words: Blue Tit, Cyanistes caeruleus, fitness, hatching delay, incubation period, laying gaps, phenotypic plasticity, timing of breeding.

\section{Alteraciones de Corto Plazo en la Secuencia de Cría Permiten a un Passeriforme lograr una Mejor Sincronía con el Pico de Disponibilidad de Alimento}

RESUMEN.-Las aves pueden, hasta cierto punto, retrasar la eclosión una vez comenzada la puesta a fin de sincronizar la fecha de eclosión con el pico de disponibilidad de alimento bien sea incrementado el intervalo de puesta entre un huevo y el siguiente o posponiendo el comienzo de la incubación. Sin embargo, los retrasos en la eclosión también pueden ser el resultado de costes energéticos ligados a las fases tempranas de la reproducción. En el presente estudio, nosotros ahondamos en el fenómeno de los retrasos en la eclosión en una población de Cyanistes caeruleus durante dos primaveras con condiciones ambientales bien diferentes. Se determinó la incidencia de pausas durante la puesta y el inicio de la incubación, así como los factores y consecuencias asociados con cada uno de estos fenómenos. Se encontró que el tamaño de puesta, la incidencia de interrupciones durante la puesta y el grado de sincronía con respecto al pico de alimento explicaron una proporción significativa de la varianza en los retrasos en la eclosión, y que este rasgo se relacionó de forma negativa con el éxito de eclosión pero de forma positiva con el peso de los polluelos. Las hembras que incrementaron el intervalo entre huevos consecutivos incurrieron en un coste en términos de probabilidad de eclosión. La incidencia de interrupciones durante la puesta fue determinada principalmente por la temperatura ambiental, lo cual sugiere que se trata de un fenómeno no deliberado. El grado de sincronía con respecto al pico de orugas fue el principal determinante de las variaciones observadas entre nidos en relación al momento de iniciar la incubación. Las hembras que adelantaron el comienzo de la incubación fueron capaces de poner más huevos y de mejor calidad en comparación con aquellas que comenzaron a incubar una vez completada la puesta o con posterioridad. Nuestro estudio evidencia que los retrasos en la eclosión surgen como resultado tanto de restricciones energéticas como de decisiones estratégicas por parte de las aves. 
MORE THAN FORTY years ago, David Lack proposed that timing of breeding in birds evolved so that the maximal demand by offspring for food coincided with the time of maximal food abundance, because this would maximize fledgling production (Lack 1968). This idea has been supported by a large number of studies of the Paridae. For this family, fledgling condition, which largely determines postfledging survival (Naef-Daenzer et al. 2001) and recruitment (Both et al. 1999), depends mainly on food supply (Naef-Daenzer and Keller 1999, Visser et al. 2006). However, for Great and Blue tits (Parus major and Cyanistes caeruleus, respectively), whose main food is lepidopteran larvae, the short period during which foraging conditions are optimal is very unpredictable because the development of caterpillars is temperature dependent (van Asch and Visser 2007 and references therein). Clearly, if the birds time reproduction so that the nestling period coincides with the annual caterpillar peak, they must start their breeding cycle in advance of that time. Hence, birds may use proximate factors (leafing phenology or ambient temperature; for a review, see Visser et al. 2004) as cues to fine tune their laying date. However, once egg laying has begun, birds have limited scope for altering their breeding schedule. Nonetheless, there are mechanisms that allow birds to better adjust their timing in response to short-term variation in environmental conditions (periods of bad weather or shifts in caterpillar phenology). This slight leeway in adapting the timing of hatching is asymmetric because the possibilities for retarding hatching date are far greater than the possibilities for accelerating the process (Van Noordwijk et al. 1995). Females can extend the nesting cycle by increasing the laying interval between successive eggs (laying gaps; e.g., Dhondt et al. 1983, Nilsson and Svensson 1993b), delaying the onset of incubation for several days (Nilsson 1994, 2000; Cresswell and McCleery 2003), or relaxing nest attentiveness during the incubation period (Cresswell and McCleery 2003). On the other hand, a shortening of the interval between the laying of the first egg and hatching could be achieved via clutch-size reduction (Nilsson 2000, Wesołowski 2000) or by starting incubation before clutch completion (Monrós et al. 1998, Visser et al. 1998).

Different hypotheses have been proposed to explain the plasticity in onset of incubation and the underlying mechanisms that cause such plasticity (for a review, see Stoleson and Beissinger 1995). However, in most cases (e.g., Monrós et al. 1998, Naef-Daenzer et al. 2004) these hypotheses were tested without distinguishing between interruptions in laying and delays in the onset of incubation. Rather, only the net result was considered (i.e., whether or not hatching was delayed). The "energy constraint hypothesis" proposes that timing of breeding might be constrained early in the season by a limited supply of energy and nutrients for egg production (Perrins 1970). Thus, worsening conditions (low temperatures or food shortage) could lead to reductions in both clutch size and egg size, as well as missed days in the laying sequence (see Nager 2006 and references therein). Energy constraints may also delay the onset of incubation, because this period is also energetically costly (e.g., Reid et al. 2000). For small passerines, such as Blue and Great tits, incubation requires as much energy as nestling provisioning (Tinbergen and Williams 2002, de Heij 2006). Therefore, the onset of incubation may be delayed as a result of either the energy expenditure by females during egg production or lack of fat-body reserves for the subsequent incubation period. Alternatively, hatching delays may be adaptive, not contingent. That is, these slight alterations in the breeding schedule may be a strategic decision by the female to match the nestling period with the peak in food abundance (Cresswell and McCleery 2003, Both and Visser 2005). To achieve this, birds could incur different costs depending on whether they delay or advance their hatching date. By starting incubation later, birds extend the amount of time their offspring are nest-bound and thus the risk of predation (Bosque and Bosque 1995). When incubation begins before clutch completion, eggs normally hatch asynchronously, and this leads to a size hierarchy among siblings that may result in brood reduction if food becomes scarce because the oldest nestlings outcompete and monopolize parental feedings. Hence, earlier hatching dates may cause a substantial reduction of fledging success when food resources are not plentiful. In this sense, hatching asynchrony is held by many as a means to that end (i.e., the "brood reduction hypothesis"; Lack 1954, Ricklefs 1965; see also Pijanowski 1992) because hatching asynchrony serves as the mechanism by which parents allocate food when food supplies are low and sibling competition is high (for a review, see Stenning 1996). Regardless, both hypotheses share the idea that the mechanisms by which breeding timetables can be sped up or slowed down are behavioral decisions of the females and in both cases such strategic decisions should ultimately result in an enhancement of the reproductive output and, thus, increased fitness.

We explored the phenomenon of hatching delays in a population of Blue Tits breeding in nest boxes in southern Europe. We quantified the occurrence of laying gaps and determined the timing of the onset of incubation that led to hatching delays and potential factors-for example, ambient temperature (Yom-Tov and Wright 1993), female body condition (Potti 1998), and nest architecture (Lombardo et al. 1995) - that could influence them. We then analyzed the effects of each of these mechanisms separately, and of hatching delays as a whole, on hatching success, nestling mass, and breeding performance. Specifically, we determined whether the incidence of laying gaps influenced hatching probability negatively, whether changes in the onset of incubation (depending on whether the birds' breeding date was early or late in relation to the food peak) affected the length of incubation, and whether hatching delays resulted in a gain in nestling mass or impaired hatching success or both. We also explored the existence of differences in clutch size, egg quality (using eggshell spotting as a proxy; see Sanz and García-Navas 2009), and female body mass among nests that had different incubation patterns or a different laying schedule. Finally, we looked for consistency in the onset of incubation across two consecutive breeding seasons within individual females. Our overall aim was to gain an understanding of the extent to which delays can be attributed to strategic decisions by the female or energetic constraints during the egg-laying or the incubation period or during both.

\section{Methods}

Study area and general field methods.-Our study was conducted in the woodlots of Quintos de Mora in central Spain (Toledo province; $\left.39^{\circ} 25^{\prime} \mathrm{N}, 4^{\circ} 04^{\prime} \mathrm{W}\right)$ during the breeding seasons of 2008 and 2009. The woodlots are dominated by Pyrenean Oak (Quercus pyrenaica) and, to a lesser extent, Zeen Oak (Q. faginea). Beginning in late March, 280 wooden nest boxes (dimensions: $12 \times 11.5 \times 16.5 \mathrm{~cm}$ ) were inspected regularly. Once laying began, nests were visited 
daily to detect laying gaps (assuming that 1 egg is laid each day). Daily inspections also allowed us to determine the onset of incubation, which we defined as the number of days that had elapsed between the laying of the last egg and either the first day that the female was found incubating or the first day that the eggs were found uncovered and warm. To that end, we checked for warmth in the eggs throughout the laying period. After clutch completion, we took a digital photograph of each egg (side view) to score the eggshell pigmentation pattern (see more below). Photographs were taken with the aid of a base and a background grid to correct for ambient light differences among photos. At the same time, the nests were removed from the nest box for a moment and weighed on an electronic balance $( \pm 0.1 \mathrm{~g})$. The height of the nest and the thickness of the nest cup are strongly correlated ( $r=0.77$; de Heij 2006). Because nest mass and height are also strongly correlated ( $r=0.57, P<0.001, n=90$ ), we used mass as an indicator of nest insulation. Around the expected hatching date, nests were visited daily to determine hatching success (proportion of eggs hatched). Because incubation in this species normally lasts 13 days (Quintos de Mora 2006-2007: $13.23 \pm 1.61, n=165)$, we calculated the expected hatching date as follows: (first egg date + clutch size +12 ). The difference between this date and the observed hatching date was taken as hatching delay (i.e., negative values denote that hatching occurred before expected, and positive values denote a delay).

Adult birds (2008: 44 females and 35 males; 2009: 77 females and 66 males) were trapped while feeding 8-day-old nestlings. All birds were individually identified with aluminium bands and sexed according to the presence or absence of a brood patch. At capture, we measured tarsus length (to the nearest $0.01 \mathrm{~mm}$ ) with a digital calliper and body mass with an electronic portable balance to the nearest $0.1 \mathrm{~g}$ following a protocol similar to that described by Perret (2004). When nestlings were 13 days old they were banded and measured in the same manner as the adults. At about day 20 after hatching, nests were visited again to establish the breeding success of each pair (i.e., proportion of eggs that resulted in fledged young).

Monitoring caterpillar phenology.-Caterpillar phenology was monitored from the oak bud-burst to the end of the season. Caterpillar surveys consisted of counts and further identification of all lepidopteran larvae found during a 5-min interval at one randomly chosen branch on the selected oak (not fixed; $\geq 6$ day $^{-1}$ dispersed over the study area). Branch samples were randomly chosen and were cut from the middle of the canopy with the aid of a skylift. These data allowed us to establish the date of peak food (i.e., caterpillar) abundance. The timing of tit breeding is considered to have evolved in response to shifts in their food supplybeing a few days earlier or later may lead to measurable differences in nestling mass and prospects of postfledging survival (e.g., Tinbergen and Boerlijst 1990, Van Noordwijk et al. 1995, Verboven et al. 2001). Hence, selection is presumably strong for parents to time their reproduction to match the period of greatest food demand by the young (about 9-10 days of age). To assess the relative timing of each breeding pair (i.e., an estimate of the degree of mismatch with the food peak), we calculated the days elapsed between the day their chicks were 9 days old and the caterpillar peak date ("synchrony" sensu Visser et al. 2006).

Temperature data.-Temperature data were obtained from nine Tinytags (Gemini Data Loggers, West Sussex, United Kingdom) installed inside empty nest boxes that were dispersed throughout the nest-box plot. Tinytags recorded ambient temperature $\left({ }^{\circ} \mathrm{C}\right)$ at 5 -min intervals. We calculated mean temperature during laying as the mean of the daily measurements from 3 days before the first egg was laid to the date of clutch completion (following Monrós et al. 1998 and references therein).

Egg speckling assessment.-As a measure of eggshell quality, we assessed the pigmentation pattern of 677 eggs (corresponding to 111 clutches) from digital photographs taken during the field work. The same observer (V.G.N.) classified the eggs on the basis of the degree of distribution of pigment spots (i.e., degree of clumping of speckles across the shell's surface, ranked in increments of 0.5 , from 1 for eggs whose spots are all on the broad end to 5 for eggs with specklings evenly distributed over the shell surface) following the protocol of Gosler et al. (2000). In our study area, this trait has been shown to be a strong predictor of hatching probability (Sanz and García-Navas 2009, García-Navas et al. 2010).

Statistical analyses.-We used 128 broods (48 in 2008, 81 in 2009) for our analyses. We used stepwise multiple regression analyses to explore variation in hatching delays in relation to the occurrence of laying gaps and the onset of incubation, along with study year, mean temperature during laying, clutch size, eggshell quality, nest mass, female body mass, and synchrony with the caterpillar peak. We then sought to explain the degree to which laying gaps and delay in the onset of incubation were related to study year, mean temperature during laying, clutch size, nest mass, eggshell spotting distribution, female body mass, mean temperature during laying, and synchrony with the caterpillar peak (or laying date). Because synchrony with the caterpillar peak and laying date were highly correlated $(r=0.76, P<0.001)$, only the one that contributed more to variation in the focal trait was entered into the model. We tested the significance of each variable by assessing the change in deviance produced by removing each from the full model.

Generalized linear mixed models (GLMM) were used to test whether hatching delays had effects on nestling condition and breeding success. We also tested whether an early onset of incubation led to improvement of nestling mass. Subsequently, we explored the existence of differences in clutch size, egg quality (spotting distribution), hatching success, and female body mass between nests in which we detected laying gaps and those in which we did not (binary variable: with or without laying gaps; $n=37$ and 92, respectively). The onset of incubation was also transformed into a categorical variable to account for the effects of such behavior on the aforementioned variables. Nests were grouped into three categories-advanced $(n=31)$, normal $(n=53)$, and delayed incubation $(n=44)$-in relation to when the female started incubation. Moreover, we looked for consistency of the onset of incubation within individual females $(n=15)$ between 2008 and 2009.

All models were initially fitted with the full set of variables that could potentially explain variation in the response variable. Final models were selected following a backward elimination procedure in which the variable with the highest $P$ values was successively dropped from the analysis so that only significant terms remained $(P<0.05)$. The significance of the remaining variables was tested again until no additional variable reached significance. The result is the minimal most adequate model for explaining the variability in the response variable, where only the significant explanatory variables are retained (Engqvist 2005). Previously, proportions (hatching success, fledgling success, and breeding success) were 
arcsine-square-root transformed before analysis to attain homoscedasticity and normality. Some sample sizes differ among analyses because not all birds were captured and nest measurements or shell spotting scores were missing for some nests. Fisher's LSD test was used for a posteriori comparisons. All $P$ values refer to twotailed tests. Data are given as means \pm SE, unless stated otherwise.

\section{Results}

Hatching delays.-Hatching delays were common during the 2008 and 2009 breeding seasons, and four variables explained the variation in hatching delays: clutch size, laying gaps, onset of incubation, and synchrony with the caterpillar peak (model: $F=21.61$, $\mathrm{df}=4$ and $69, P<0.001, R^{2}=0.53$ ). As expected, the delays were positively correlated with both onset of incubation and laying gaps (Table 1). Eighty-six percent $(n=79)$ of females whose clutches hatched later than expected started incubation one or more days after the last egg was laid. In $45 \%$ of cases in which hatching occurred earlier than expected, females initiated incubation prior to clutch completion. On the other hand, we observed interruptions during the laying sequence in $68 \%$ of nests in which hatching date was delayed. Furthermore, the magnitude of hatching delays decreased as the degree of synchrony with the caterpillar peak date (Table 1) and clutch size increased (Table 1).

Hatching delays had a significant negative effect on hatching success because hatching success declined as the number of days elapsed between the expected hatching date and the observed date increased (GLMM, $F=6.22, \mathrm{df}=1$ and $83, P=0.02$; Fig. $1 \mathrm{~A}$ ). Low breeding success was also negatively associated with hatching delays and positively associated with eggshell spotting (GLMM year: $F=9.90, \mathrm{df}=1$ and $83, P<0.01$; eggshell spotting distribution: $F=$ 4.99, $\mathrm{df}=1$ and $83, P=0.03$; hatching delay: $F=6.41, \mathrm{df}=1$ and 83 , $P=0.01 ; \beta=-0.26)$. By contrast, nestlings from clutches in which hatching date was postponed were heavier even after we controlled for brood size (GLMM, hatching delay: $F=4.27, \mathrm{df}=1$ and 96, $P=0.04$; brood size: $F=8.43, \mathrm{df}=1$ and $97, P=0.01$; Fig. $1 \mathrm{~B})$.

TABLE 1. Multiple regression of hatching delays (days, dependent variable) in relation to clutch size, laying gaps, onset of incubation, and synchrony with the caterpillar peak $\left(R^{2}\right.$ adj. $=0.53 ; n=74$ broods for Blue Tits breeding in Quintos de Mora, Spain, in 2008 and 2009). The full model also included the following explanatory variables: study year, eggshell quality (speckling pattern), nest mass, female body mass, and mean temperature during laying.

\begin{tabular}{lrlccc}
\hline & Estimate & SE & df & $t$ & $P$ \\
\hline Explanatory terms & & & & & \\
$\quad$ Clutch size & -0.25 & 0.11 & 69 & 2.30 & 0.02 \\
$\quad$ Laying gaps & 0.54 & 0.09 & 69 & 6.99 & $<0.001$ \\
Onset of incubation & 0.27 & 0.10 & 69 & 2.56 & 0.01 \\
$\quad$ Synchrony with the & -0.28 & 0.13 & 69 & 2.23 & 0.03 \\
$\quad$ caterpillar peak & & & & & \\
Deleted terms & & & & & \\
$\quad$ Study year & -0.66 & 0.11 & 68 & 1.64 & 0.10 \\
Temperature & -0.02 & 0.12 & 67 & 0.20 & 0.84 \\
Eggshell quality & -0.37 & 0.29 & 66 & 1.29 & 0.20 \\
$\quad$ Nest weight & 0.01 & 0.02 & 65 & 0.12 & 0.90 \\
Female body mass & 0.03 & 0.32 & 64 & 0.08 & 0.94 \\
\hline
\end{tabular}
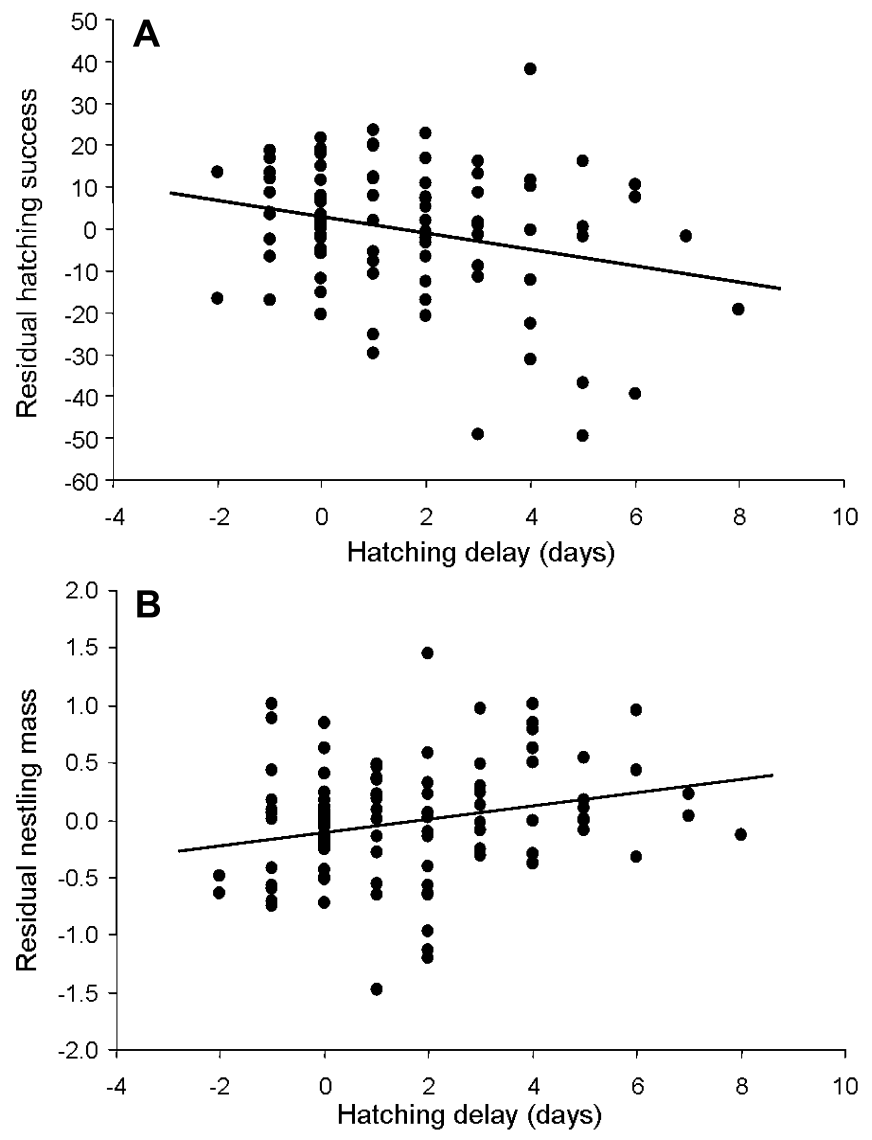

FIG. 1. Relation between hatching delays and (A) hatching success and (B) nestling body mass of Blue Tits. Delays refer to the number of days elapsed between the expected hatching date and the observed one. Hatching success is expressed as statistical residuals obtained after controlling for eggshell spotting distribution (year: $F=6.91, \mathrm{df}=1$ and 84 , $P=0.01$; eggshell spotting distribution: $F=8.22, \mathrm{df}=1$ and $84, P<0.01$ ). Nestling body mass is expressed as statistical residuals obtained after controlling for other influencing variables (nestling tarsus length: $F=22.80$, $\mathrm{df}=1$ and $97, P<0.001$; brood size: $F=8.43, \mathrm{df}=1$ and $97, P=0.01$ ).

Onset of incubation.-Incubation period ranged from 10 to 19 days (2008: $14.9 \pm 0.2 ; 2009$ : $13.6 \pm 0.2$ ), but most birds (2008: 64.6\%; 2009: 59.2\%) exhibited an incubation period longer than usual in this species ( 13 days), whereas a minor proportion of females (2008: 19.7\%; 2009: 18.8\%) showed a hatching date earlier than expected. Our multiple regression showed that the length of incubation decreased as the season progressed (GLMM, $F=$ 23.70, $\mathrm{df}=1$ and $80, P<0.001 ; \beta=-0.53$, ) and was positively related to clutch size (GLMM, $F=15.79$, $\mathrm{df}=1$ and $80, P<0.001$; $\beta=0.37$ ). Females that began incubation earlier had a shorter incubation period than females that began incubation on the day of clutch completion or later (GLMM, $F=9.34, \mathrm{df}=1$ and $103, P<$ 0.01; Fig. 2). The multiple regression model showed that the onset of incubation depended on both the synchrony with the caterpillar peak and ambient temperature (model: $F=54.43, \mathrm{df}=2$ and $71, P<0.001, R^{2}=0.59$; temperature: $t=2.63, \mathrm{df}=71, P=0.01, \beta=$ -0.22 ). The extent of synchrony with the caterpillar peak was the 


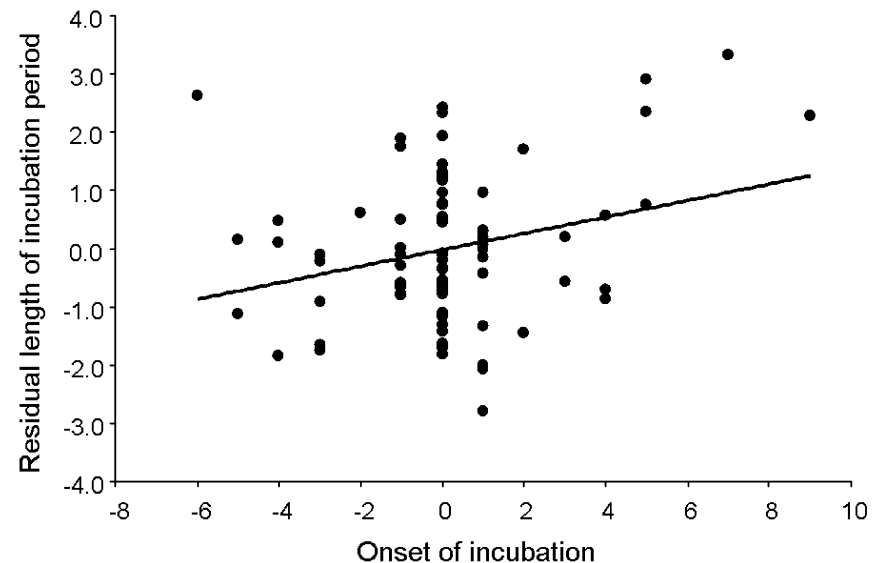

FIG. 2. The length of the incubation period was associated positively with the onset of incubation in relation to clutch completion in Blue Tits. The incubation period is expressed as statistical residuals after controlling for laying date and clutch size.

main predictor of the onset of incubation (Fig. $3 ; t=7.74, \mathrm{df}=71$, $P<0.001, \beta=-0.65)$. Clutch size, nest mass, female body mass, and egg quality had no influence on the onset of incubation (all $P>$ $0.05)$. Incubation began as early as 6 days before clutch completion and as late as 9 days after (Fig. 3).

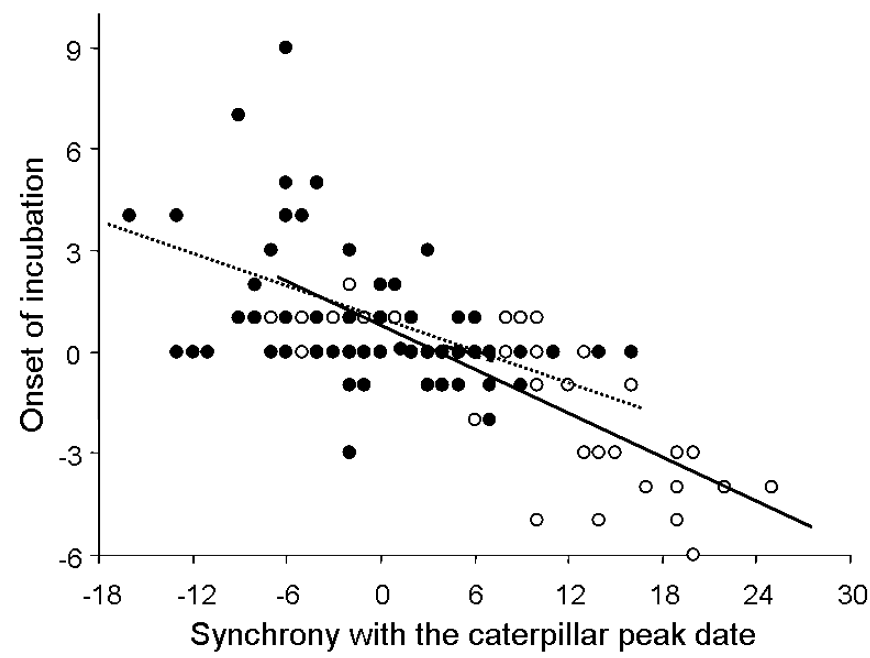

FIG. 3. Relation between onset of incubation and synchrony with the caterpillar peak date (synchrony $=$ hatch date +9 - caterpillar peak date, where 9 = modal brood size; see text for details) in 2008 (empty dots, continuous regression line) and 2009 (filled dots, dotted regression line). Negative scores on onset of incubation indicated that females started incubation before clutch completion, whereas negative values for synchrony with the caterpillar peak indicated an early timing in relation to the peak. Shown are the attempts the Blue Tits made in both years to achieve a better synchronization with the timing of maximum food availability, which occurred on 5-6 May and 14-15 May in 2008 and 2009, respectively. In 2009, female Blue Tits tended to wait several days after clutch completion before they started incubating, whereas in the previous year it was not unusual to find females incubating incomplete clutches.

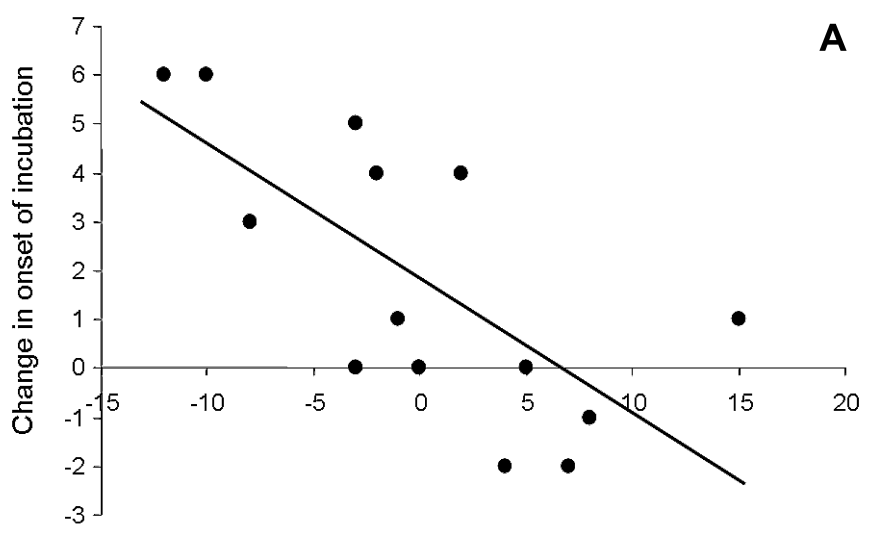

Relative change in laying date

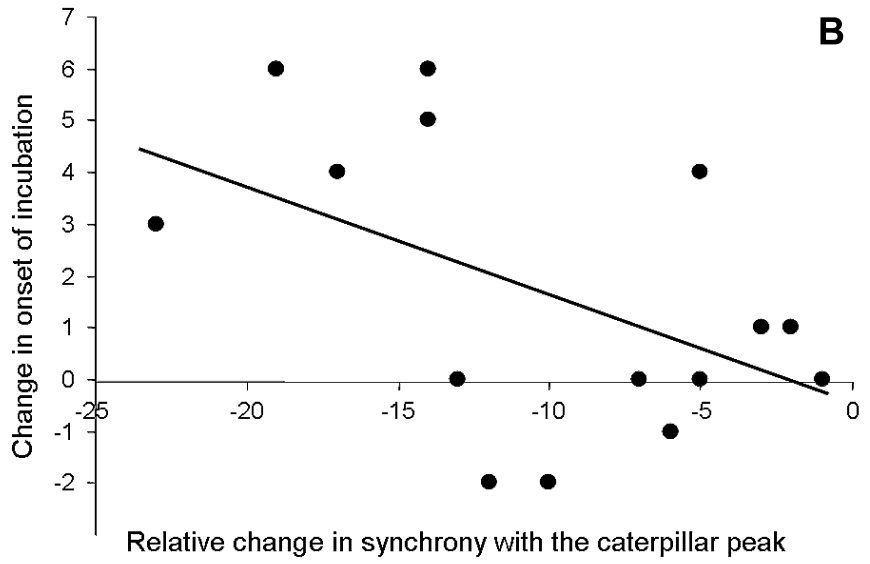

FIG. 4. Variation in onset of incubation across two successive breeding seasons (2008 and 2009) within individual female Blue Tits $(n=15)$ in relation to relative changes in $(A)$ laying date and (B) synchrony with the caterpillar peak. Negative values for onset of incubation were earlier, negative values for relative change in laying date indicated an earlier laying in the second year, and a negative score on change in synchrony meant an earlier timing in relation to the peak.

When we analyzed the between-year changes in the onset of incubation, we confirmed variation in this trait at an individual level. In the second year, all recaptured females $(n=15)$ were earlier with respect to the food peak and most of them tended to delay the start of incubation. Analyses indicated that betweenyear changes in incubation behavior were related to between-year changes in laying date $(F=11.66, \mathrm{df}=1$ and $13, P<0.01$; Fig. $4 \mathrm{~A})$ and synchrony with the caterpillar peak $(F=4.34, \mathrm{df}=1$ and 13 , $P=0.057$; Fig. 4B). Nestling physical condition was unrelated to the onset of incubation. There were no differences in either body mass or tarsus length between nestlings from clutches with different incubation patterns (all $P>0.05$ ). Nor did intrabrood variance in nestling mass differ significantly in relation to the incubation pattern (advanced: $0.68 \pm 0.02$, delayed: $0.72 \pm 0.03$, normal incubation schedule: $0.72 \pm 0.03 ; F=0.87, \mathrm{df}=2$ and $119, P=0.42$ ).

When the nests were grouped into three categories according to the onset of incubation (advanced, delayed, and normal incubation schedules) we found that females that advanced the onset of incubation laid larger clutches than those that began incubation 

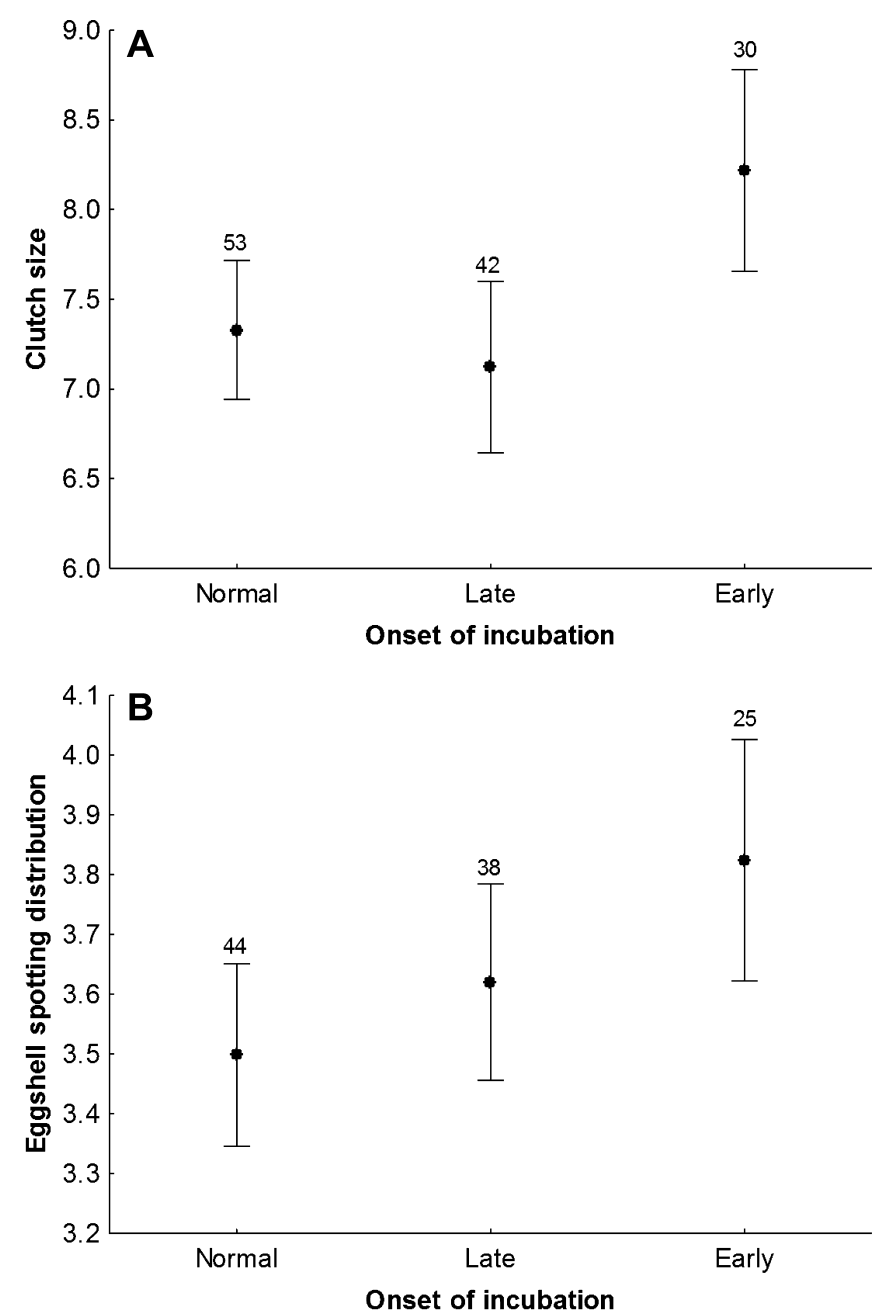

FIG. 5. Differences in (A) clutch size and (B) eggshell spotting distribution among nests of Blue Tits in which incubation began before clutch completion ("early"), nests in which females initiated incubation after the last egg was laid ("normal"), and nests in which females waited one or several day after clutch completion to start to incubate ("late"). Higher values of eggshell spotting distribution denote a wider distribution of pigment spots over the shell surface. Lower values of speckling assessments corresponded to eggs with the spots concentrated around the blunt end, which results in lower hatching probability. Sample sizes (number of nests) are indicated above the bars. Means are given \pm SE.

after clutch completion or later (GLMM, laying date: $F=34.71$, $\mathrm{df}=1$ and 121, $P<0.001$; onset of incubation: $F=4.32, \mathrm{df}=2$ and $121, P=0.01$; Fig. 5A). In addition, we found a significant difference in eggshell quality among these groups even after we controlled for laying date and clutch size; birds that began incubation prior to clutch completion laid eggs with spots more widely distributed over the shell surface (GLMM, $F=3.25, \mathrm{df}=2$ and 104, $P=0.04$; Fig. 5B). Meanwhile, females that started to incubate earlier did not differ from those that started to incubate with the last egg or later in either size or body mass (female tarsus length: $F=1.37, \mathrm{df}=$ 2 and $112, P=0.26$; female mass: $F=0.18, \mathrm{df}=2$ and $109, P=0.83$ ).
Regarding reproductive success, there was no effect of variation in the onset of incubation on either hatching success or the proportion of fledged young (hatching success: $F=0.16, \mathrm{df}=2$ and 122 , $P=0.85$; breeding success: $F=0.30, \mathrm{df}=2$ and $109, P=0.74$ ).

Laying gaps. - Interruptions during egg laying were similar in frequency in both years (2008: $72.9 \%, n=48 ; 2009: 70.3 \%, n=81)$. The mean length of the interruptions was 2 days (2008: $2.0 \pm 1.14$ days, range: $0-6$; 2009: $2.1 \pm 6.74$ days, range: $0-4)$. Laying date, clutch size, female body mass, and synchrony with the caterpillar peak had no influence on the incidence of laying gaps, but laying gaps were more common at low mean temperature during egg laying, even after the effects of timing of breeding were accounted for statistically (model: $F=18.22, \mathrm{df}=1$ and $72, P<0.001, R^{2}=$ 0.19 ; temperature: $t=4.26, \mathrm{df}=72, P<0.001, \beta=-0.45)$. When the nests were divided into those with (1) or without (0) laying gaps, we found no differences in clutch size, egg quality, or female body mass between groups (all $P>0.05$ ). Lastly, a significant interaction between laying gaps and study year for both hatching and breeding success was found (GLMM, hatching success: year, $F=11.46$, $\mathrm{df}=1$ and $82, P=0.001$; eggshell spotting distribution, $F=8.78, \mathrm{df}=$ 1 and $82, P<0.01$; laying gaps, $F=3.57, \mathrm{df}=1$ and $82, P=0.06$; year*laying gaps, $F=3.79, \mathrm{df}=1$ and $82, P=0.05$; breeding success: year, $F=12.32$, $\mathrm{df}=1$ and $83, P<0.001$; eggshell spotting distribution, $F=7.88, \mathrm{df}=1$ and $82, P<0.01$; laying gaps, $F=3.60, \mathrm{df}=1$ and $82, P=0.06$; year*laying gaps, $F=4.45, \mathrm{df}=1$ and $82, P=0.04$ ). Post hoc comparisons revealed that laying interruptions were associated with lower hatching success and lower breeding success only in the cooler breeding season (LSD test, hatching success: 2008, $P=0.02$; 2009, $P=0.84$; breeding success: $2008, P=0.02 ; 2009, P=$ $0.95)$. The proportion of hatchlings that resulted in fledged young (i.e., fledgling success) did not differ between nests with and without laying interruptions $(F=2.42, \mathrm{df}=1$ and $126, P=0.12)$.

\section{Discussion}

Determinants and fitness consequences of hatching delays.-We have identified some of the factors associated with hatching delays, and the two phenomena linked to variation in the timing of hatching: interruptions in the laying sequence and delays in the timing of the start of incubation. The extent of synchrony with the caterpillar peak date was also an important predictor of the extent of hatching delays. Furthermore, delays were more frequent during the unfavorable spring of 2008 than in 2009. In contrast to previous studies (Monrós et al. 1998, Naef-Daenzer et al. 2004), we did not find a significant relationship between hatching delays and the mean temperature during the laying period.

We also found that hatching delays had both costs and benefits for the reproductive variables that we monitored. Greater delays were associated with lower hatching success, as has been previously described for Great Tits (Naef-Daenzer et al. 2004, de Heij 2006). The negative effect of delays on hatching success is likely to arise as a consequence of increased exposure time of unincubated eggs to ambient temperatures (see Drent 1975 and references therein). Hence, the likelihood of unsuccessful hatching could increase when the duration of this limiting period is prolonged as a consequence of variation in the laying interval (egg skipping) or delays in the onset of incubation (Drent 1975). Our data suggest that laying gaps had a more detrimental influence on hatching success 
than delays in the onset of incubation (discussed below). Moreover, chicks that hatched from delayed broods were heavier than those from broods that hatched when expected. Presumably, this effect arose because the postponement of hatching allowed birds to achieve better synchronization with the peak in caterpillar abundance (which largely determines nestling mass; see above), as has been shown for Great Tits (Naef-Daenzer et al. 2004). The positive effect of delayed hatching on nestling mass could lead to a net gain in fitness, because many studies have shown that fledgling mass largely determines postfledging survival in this and related species (e.g., Naef-Daenzer et al. 2001, Greño et al. 2008). With regard to the effect of the delays on hatching success, we do not assume that hatching delays constitute a deliberate attempt to induce hatching asynchrony (and thereby reduce family size) because the reduction of family size took place in the egg phase and not during the nestling period. In fact, we found dead chicks in only 9 of 129 nests. That is, because brood reduction in its strictest sense is hypothesized to occur through sibling competition, we consider that in our population hatching asynchrony may actually be an epiphenomenon of hatching delays rather than a strategy per se. On the other hand, we rarely found runts. This suggests that in our study population, eggs probably hatched within a 24 -h period (a common pattern in many passerines in which only the last egg may hatch a day later than the others; Clark and Wilson 1981), preventing significant age differences (V. García-Navas pers. obs.). This fact, together with the low prevalence of ectoparasites found in our study area (V. García-Navas and J. J. Sanz unpubl. data), argues against the brood reduction hypothesis.

When to start to incubation? A strategic decision.-Onset of incubation was determined by both temperatures during laying and synchrony with the caterpillar peak. Moreover, females exhibited phenotypic plasticity in their ability to adjust the onset of incubation to the prevailing conditions of the breeding season. In the 2008 breeding season, when cool temperatures and rainy periods were the rule, females advanced the onset of incubation, presumably because they were unable to lay earlier or they were unable to correctly predict the moment of maximum food availability because of the slow development of caterpillars as a result of bad weather. By contrast, the spring of 2009 was initially warm and breeding started early, but temperatures dropped around midApril and birds tended to delay the beginning of incubation (Fig. 3). Long-term studies of Great Tits have shown that birds compensate for their degree of mismatch with respect to the timing of the food peak by reducing or increasing the time interval between the laying of the first egg and hatching. Such behavior has been postulated to result from strategic decisions rather than from physiological limitations (Visser et al. 1998, Cresswell and McCleery 2003). In addition, the observed variation in onset of incubation was also corroborated at the individual level (Fig. 4), indicating that individuals can modify the onset of incubation in relation to clutch completion across seasons, depending on proximate factors. Our results support the idea that incubation patterns may have evolved as a plastic response to environmental cues that predict subsequent food availability (Naef-Daenzer et al. 2004, Stenning 2008).

Among the breeding parameters that we examined, an early onset of incubation was associated with a shorter incubation period even after we statistically accounted for laying date and clutch size. This agrees with a previous Blue Tit study (Nilsson and
Svensson 1993a) that showed that the seasonal reduction in the time from clutch completion to midhatching depends on the start of incubation and not on incubation efficiency. A similar trend has also been reported in Black Kites (Milvus migrans; Viñuela 1997) and Wood Ducks (Aix sponsa; Hepp 2004). Concerning the effect of possible factors that might influence incubation period, we found no effect of nest properties on the onset of incubation. This is in contrast to the earlier study on Great Tits by de Heij (2006), in which the delay in the onset of incubation was negatively related to nest thickness. Nonetheless, such a study relies on correlations and, thus, de Heij's (2006) finding may also be attributable to the influence of other variables, such as the quality of the nest builder (i.e., female condition; Tomás et al. 2006; Mainwaring and Hartley $2008,2009)$. Therefore, experimental work is necessary to test the causal pathways among these variables.

Alternatively, we found that early onset of incubation was significantly associated with a large clutch size, which is consistent with findings in Spanish Pied Flycatchers (Ficedula hypoleuca; Potti 1998). Furthermore, females that started incubating earlier laid eggs with spots more widely distributed over the shell surface (i.e., eggs of better quality). This may indicate that an early onset of incubation requires a high energy demand that only highquality females can meet, as suggested by Nilsson and Svensson (1993a). The latter authors showed that females supplemented with extra food initiated incubation earlier than control females. Nevertheless, we found no evidence of a difference in female condition at the end of the nestling period among nests with different incubation patterns. This discrepancy between our findings and those of Nilsson and Svensson (1993a) is difficult to explain, but we note that feeding experiments are not able to distinguish whether the onset of incubation is energetically constrained or whether food supplies are used as a cue by birds to predict the ensuing caterpillar peak (e.g., Gienapp and Visser 2006). Moreover, Nilsson and Svensson's (1993a) work contradicts the prediction of the brood-reduction-hypothesis that when food is scarce, hatching asynchrony (and, thus, early onset of incubation as a means to achieve it) should be greater than when food is plentiful. The present study also provides no evidence for this hypothesis, because we did not find a difference in the proportion of fledged young in relation to onset of incubation. Because we did not monitor hatching spread, we are unaware of whether those birds that started incubation sooner in relation to clutch completion experienced greater hatching asynchrony. That being the case, we would have expected to find differences in nestling survival among nests with different incubation schedules, but we did not. Nor were there differences among groups in nestling mass, which contrasts with what the brood reduction hypothesis posits. Finally, we did not find a greater difference in body mass between the largest and the smallest chick in the broods in which the female began to incubate before the clutch was completed; intrabrood variance in nestling mass did not differ significantly among nests with different incubation schedules (see above). In light of the brood reduction hypothesis, we can make another prediction: if females start to incubate earlier in order to create size hierarchies to facilitate brood reduction, we would have expected to find a decrease in egg quality with the laying sequence (i.e., birds would invest less effort in pigment production of the last eggs) to further promote the loss of surplus progeny when necessary. This prediction was 
not supported. Although eggs were not marked individually, we did not detect a decrease in eggshell quality through the laying sequence for those clutches in which incubation began before the last egg was laid (V. García-Navas pers. obs.); in fact, such clutches showed the higher mean values of speckling assessments.

Lastly, an alternative explanation is that earlier onset of incubation in larger clutches serves as a time-saving mechanism that female Blue Tits could use if they saw caterpillars emerging before reaching a peak. Females that stop laying earlier and lay smaller clutches do not need to rush the breeding schedule. Meanwhile, the association found between the onset of incubation and egg quality could be explained by the fact that in our study area, the distribution of eggshell spotting is positively correlated with clutch size (Sanz and García-Navas 2009). Overall, the observed flexibility in the start of incubation in two very different seasons is consistent with Stenning's (2008) suggestion that the onset of incubation in this species is under the influence of proximate factors (e.g., phenology of caterpillars) that could act as cues to trigger the beginning of incubation independently of clutch completion.

Laying gaps and energetic constraints.-Temperature during laying was a strong predictor of the occurrence of laying gaps. Blue Tits were more likely to show an interruption of egg laying during episodes of bad weather, which was most likely a consequence of energetic constraints (Dhont et al. 1983, Graveland and Berends 1997, Lessells et al. 2002). Experimental studies have shown that laying gaps become less frequent when supplemental food is provided (Nilsson and Svensson 1993b) or nest temperature increases (Yom-Tov and Wright 1993). Hence, missed days during egg laying were likely a nondeliberate phenomenon derived from the high costs of egg production during adverse environmental conditions rather than a strategic decision. In addition, we found that laying interruptions detrimentally influenced Blue Tits' hatching success, presumably because the viability of unincubated eggs declined over time (Drent 1975). Because laying-incubation overlaps (shortening the incubation to gain time) were detected in some nests in which we detected laying gaps (leading to delays in the onset of incubation), it seems that these alterations of the breeding schedule are a result of either fixed (physiological) or adaptive (proximate basis) processes. Thus, laying interruptions presumably represent immediate costs that females sometimes incur for breeding too early.

Hatching delays: A facultative or obligate phenomenon?-We have shown that both energy constraints (laying gaps) and strategic decisions (onset of incubation) modulate the incidence and magnitude of hatching delays in Mediterranean Blue Tits. Therefore, hatching delays are shaped by factors that act at both the proximate (immediate environment) and ultimate (natural selection) levels. On the other hand, our results do not constitute support for the view that hatching asynchrony (and, by extension, an early start to incubation) is an adaptive mechanism that evolved as a strategy to maximize fitness through brood reduction under unpredictable food levels. Our data are in agreement with the conclusions of Hõrak (1995), who stated that brood reduction seems to be a nonadaptive and unavoidable byproduct of underlying proximate mechanisms that influence egg or chick formation (so-called "adaptive decision taking"). This might explain why natural selection has not eliminated this strategy when there are other mechanisms to achieve the same goal with a smaller investment of time and energy
(Lobato et al. 2006). Our data suggest that phenotypic plasticity arising from behavioral flexibility by Blue Tits in response to proximate factors (underlying so-called reproductive decision making) can account for the observed annual differences in incubation patterns. The potential benefits of being able to strategically modify incubation behavior to optimally time breeding could selectively favor a plastic response, as occurs with other life-history traits that influence fitness (i.e., microevolutionary processes; Cresswell and McCleery 2003). However, it is only possible for Blue Tits to take advantage of this potential mechanism to compensate for unpredictability in the peak of caterpillar abundance if their start to breeding is not constrained, which is a topic of particular relevance given projections of future climate change.

\section{ACKNOWLEDGMENTS}

We thank J. M. Sebastián, C. Rodríguez Vigal, and the rest of the staff of Centro Quintos de Mora (Ministerio de Medio Ambiente) for the facilities offered to work in this restricted area. Two anonymous reviewers provided constructive comments on the manuscript. V.G.N. was supported by an FPI grant (Ministerio de Ciencia e Innovación-European Social Fund). This study was funded by the project GCL2007-61395 (Ministerio de Ciencia e Innovación).

\section{Literature Cited}

Bosque, C., AND M. T. Bosque. 1995. Nest predation as a selective factor in the evolution of developmental rates in altricial birds. American Naturalist 145:234-260.

Both, C., AND M. E. Visser. 2005. The effect of climate change on the correlation between avian life-history traits. Global Change Biology 11:1606-1613.

Both, C., M. E. Visser, And N. Verboven.1999. Density-dependent recruitment rates in Great Tits: The importance of being heavier. Proceedings of the Royal Society of London, Series B 266:465469.

CLARK, A. B., AND D. S. Wilson. 1981. Avian breeding adaptations: Hatching asynchrony, brood reduction, and nest failure. Quarterly Review of Biology 56:253-277.

Cresswell, W., and R. H. McCleery. 2003. How Great Tits maintain synchronization of their hatch date with food supply in response to long-term variability in temperature. Journal of Animal Ecology 72:356-366.

DE HEIJ, M. E. 2006. Costs of avian incubation: How fitness, energetics and behaviour impinge on the evolution of clutch size. Ph.D. dissertation, University of Groningen, Groningen, The Netherlands.

Dhondt, A. A., R. EyCKerman, AND J. Hublé. 1983. Laying interruptions in tits Parus spp. Ibis 125:370-376.

Drent, R. H. 1975. Incubation. Pages 333-420 in Avian Biology (D. S. Farner and J. R. King, Eds.). Academic Press, New York.

ENGQVIST, L. 2005. The mistreatment of covariate interaction terms in linear model analyses of behavioural and evolutionary ecology studies. Animal Behaviour 70:967-971.

García-Navas, V., J. J. Sanz, S. Merino, J. Martínez-de la Puente, E. lobato, S. del Cerro, J. Rivero, R. Ruiz de Castañeda, And J. Moreno. 2011. Experimental evidence for the role of calcium in eggshell pigmentation pattern and breeding 
performance in Blue Tits Cyanistes caeruleus. Journal of Ornithology 152:71-82.

Gienapp, P., AND M. E. Visser. 2006. Possible fitness consequences of experimentally advanced laying dates in Great Tits: Differences between populations in different habitats. Functional Ecology 20:180-185.

Gosler, A. G., P. R. Barnett, and S. J. Reynolds. 2000. Inheritance and variation in eggshell patterning in the Great Tit Parus major. Proceedings of the Royal Society of London, Series B 267:2469-2473.

Graveland, J., and A. E. Berends. 1997. Timing of the calcium intake and effect of calcium deficiency on behaviour and egg laying in captive Great Tits, Parus major. Physiological Zoology 70:74-84.

Greño, J. L., E. J. Belda, ANd E. BArba. 2008. Influence of temperatures during the nestling period on post-fledging survival of Great Tit Parus major in a Mediterranean habitat. Journal of Avian Biology 39:41-49.

Hepp, G. R. 2004. Early onset of incubation by wood ducks. Condor 106:182-186.

HõRAK, P. 1995. Brood reduction facilitates female but not offspring survival in the Great Tit. Oecologia 102:514-519.

LACK, D. 1954. The Natural Regulation of Animal Numbers. Clarendon Press, London.

LACK, D. 1968. Ecological Adaptions for Breeding in Birds. Methuen, London.

Lessells, C. M., N. J. Dingemanse, And C. Both. 2002. Egg weights, egg component weights, and laying gaps in Great Tits (Parus major) in relation to ambient temperature. Auk 119: 1091-1103.

Lobato, E., J. Moreno, S. Merino, J. J. Sanz, E. Arriero, J. Morales, G. Tomás, And J. Martínez-de la Puente. 2006. Maternal clutch reduction in the Pied Flycatcher Ficedula hypoleuca: An undescribed clutch size adjustment mechanism. Journal of Avian Biology 37:637-641.

Lombardo, M. P., R. M. Bosman, C. A. Faro, S. G. Houteman, AND T. S. KLUisza. 1995. Effect of feathers as nest insulation on incubation behavior and reproductive performance of Tree Swallows (Tachycineta bicolor). Auk 112:973-981.

Mainwaring, M. C., and I. R. Hartley. 2008. The weight of female-built nests correlates with female but not male quality in the Blue Tit Cyanistes caeruleus. Acta Ornithologica 43:43-48.

Mainwaring, M. C., And I. R. Hartley. 2009. Experimental evidence for state-dependent nest weight in the Blue Tit, Cyanistes caeruleus. Behavioural Processes 81:144-146.

Monrós, J. S., E. J. BeldA, AND E. BARBA. 1998. Delays of the hatching dates in Great Tits Parus major: Effects on breeding performance. Ardea 86:213-220.

Naef-Daenzer, B., And L. F. Keller. 1999. The foraging performance of Great and Blue tits (Parus major and P. caeruleus) in relation to caterpillar development, and its consequence for nestling growth and fledging weight. Journal of Animal Ecology 68:708-718.

Naef-Daenzer, B., F. Widmer, And M. Nuber. 2001. Differential post-fledging survival of Great and Coal Tits in relation to their condition and fledging date. Journal of Animal Ecology 70:730-738.
Naef-Daenzer, L., R. G. Nager, L. G. Keller, and B. NaefDAENZER. 2004. Are hatching delays a cost or a benefit for Great Tit Parus major parents? Ardea 92:229-238.

NAger, R. G. 2006. The challenges of making eggs. Ardea 94:323346.

NiLSSON, J.-Å. 1994. Energetic bottle-necks during breeding and the reproductive cost of being too early. Journal of Animal Ecology 63:200-208.

NiLSSON, J. A. 2000. Time-dependent reproductive decisions in the Blue Tit. Oikos 88:351-361.

Nilsson, J. Å., AND E. Svensson. 1993a. Energy constraints and ultimate decisions during egg-laying in the Blue Tit. Ecology 74:244-251.

Nilsson, J. Å., And E. Svensson. 1993b. The frequency and timing of laying gaps. Ornis Scandinavica 24:122-126.

Perret, P. 2004. Suivi de la phénologie de la reproduction de la mésange bleue Parus caeruleus. Manual de protocoles. [Online.] Available at www.cefe.cnrs.fr/esp/pdf/PP_SuiviRepro_def.pdf.

Perrins, C. M. 1970. The timing of birds' breeding seasons. Ibis 112:242-255

PIJANOwSKI, B. C. 1992. A revision of Lack's brood reduction hypothesis. American Naturalist 139:1270-1292.

Pотті, J. 1998. Variation in the onset of incubation in the Pied Flycatcher (Ficedula hypoleuca): Fitness consequences and constraints. Journal of Zoology (London) 245:335-344.

Reid, J. M., P. Monaghan, and G. D. Ruxton. 2000. Resource allocation between reproductive phases: The importance of thermal conditions in determining the cost of incubation. Proceedings of the Royal Society of London, Series B 267:37-41.

RICKLEFS, R. E. 1965. Brood reduction in the Curved-billed Thrasher. Condor 67:505-510.

SANZ, J. J., AND V. GARCíA-NAVAS. 2009. Eggshell pigmentation pattern in relation to breeding performance of Blue Tits Cyanistes caeruleus. Journal of Animal Ecology 78:31-41.

STENNING, M. J. 1996. Hatching asynchrony, brood reduction and other rapidly reproducing hypotheses. Trends in Ecology \& Evolution 11:243-246.

STENNING, M. J. 2008. Hatching asynchrony and brood reduction in Blue Tits Cyanistes caeruleus may be a plastic response to local oak Quercus robur bud burst and caterpillar emergence. Acta Ornithologica 43:97-106.

StOleson, S. H., AND S. R. Beissinger. 1995. Hatching asynchrony and the onset of incubation in birds, revisited. When is the critical period? Pages 191-270 in Current Ornithology, vol. 12 (D. M. Power, Ed.). Plenum Press, New York.

Tinbergen, J. M., And M. C. Boerlijst. 1990. Nestling weight and survival in individual Great Tits (Parus major). Journal of Animal Ecology 59:1113-1127.

Tinbergen, J. M., And J. B. Williams. 2002. Energetics of incubation. Pages 299-313 in Avian Incubation: Behaviour, Environment, and Evolution (D. C. Deeming, Ed.). Oxford University Press, New York.

Tomás, G., S. Merino, J. Moreno, J. J. Sanz, J. Morales, and S. García-Fraile. 2006. Nest weight and female health in the Blue Tit (Cyanistes caeruleus). Auk 123:1013-1021.

VAN ASCH, M., AND M. E. VISSER. 2007. Phenology of forest caterpillars and their host trees: The importance of synchrony. Annual Review of Entomology 52:37-55. 
Van Noordwijk, A. J., R. H. McCleery, and C. M. Perrins. 1995. Selection for the timing of Great Tit breeding in relation to caterpillar growth and temperature. Journal of Animal Ecology 64:451-458.

Verboven, N., J. M. Tinbergen, and S. Verhulst. 2001. Food, reproductive success and multiple breeding in the Great Tit Parus major. Ardea 89:387-406.

VIÑUELA, J. 1997. Laying order affects incubation duration in the Black Kite (Milvus migrans): Counteracting hatching asynchrony. Auk 114:192-199.

Visser, M. E., C. Both, And M. M. Lambrechts. 2004. Global climate change leads to mistimed avian reproduction. Pages 89-110 in Birds and Climate Change: Advances in Ecological Research (A. P. Møller, W. Fiedler, and P. Berthold, Eds.). Elsevier, London.
Visser, M. E., L. J. M. Holleman, And P. Gienapp. 2006. Shifts in caterpillar biomass phenology due to climate change and its impact on the breeding ecology of an insectivorous bird. Oecologia 147:164-172.

Visser, M. E., A. J. Van NoordwiJk, J. M. Tinbergen, and C. M. LESSELLS. 1998. Warmer spring lead to mistimed reproduction in Great Tits (Parus major). Proceedings of the Royal Society of London, Series B 265:1867-1870.

Wesolowski, T. 2000. Time-saving mechanisms in the reproduction of Marsh Tits Parus palustris. Journal of Ornithology 141:309-318.

YoM-Tov, Y., AND J. WRIGHT. 1993. Effect of heating nest boxes on egg laying in the Blue Tit (Parus caeruleus). Auk 110:95-99.

Associate Editor: R. D. Dawson 